\title{
In the Future, Learning in the Cloud Will be More Effective than Learning in A Physical University
}

\author{
Jiayu Zhou \\ University of York, York, YO10 5DD, UK
}

\section{ARTICLE INFO}

Article history

Received: 3 October 2020

Revised: 6 October 2020

Accepted: 9 October 2020

Published Online: 16 October 2020

Keywords:

Learning in the cloud

Physical university

Effective

\begin{abstract}
With the progress of technology, learning in the cloud has becoming the new teaching and learning model in education. Compared with the traditional class, it influences on improving academic performance, stimulating learning motivation and saving time. However, most changeling of it is increased of dropout. What is more, the feeling of lacking interpersonal communication happened between the teachers and students.
\end{abstract}

Learning in the cloud has especially in the colleges, however, become the main learning method of some courses, with its proponents claiming that it is beneficial for the students since its learning resources do not be limited at the university which can help students gain more useful and valuable course information. However, its opponents argue that E-learning is not the best way for students in college to study. It requires more intense self-discipline, and there is an additional fear that it may require more homework and assignments than a traditional class. These critics further argue that adult education classes need a more interactive learning environment to contribute to self-direction and critical thinking.

This paper attempts to assess the availability of learning in the cloud, in comparison with classroom lessons. The main argument for defining learning in the cloud is first discussed, followed by analyzing the strengths and

*Corresponding Author:

Jiayu Zhou,

University of York, York, YO10 5DD, UK;

E-mail:940466022@qq.com. 
limitations of this learning-mode. Finally, Compared different students learning in the cloud.

\section{Definition and Strengths of Learning in the Cloud}

Many experts have attempted to define cloud learning, but in fact, no specific and standard definition has been given up to now because the Information Communication Technology (ICT) has been being developed. There are two experts, Dudeney and Hockly (2012) defined it as being the ability of teachers and learners to build the relationship with the global world and accepted globally educated by the social web and mobile technologies ${ }^{[2]}$. E-learning, as a real revolution of distance learning, uses the newest technology to teach students (Sangrà, Vlachopoulos and Cabrera, 2012). They also pointed out that e-learning, as a new method improves the existing pattern of traditional education (ibid).

Academic performance is improved during the group of student's period university's studies by learning in the cloud. Dudeney and Hockly(2012) found that students can easily access online databases and experts in online classrooms ${ }^{[2]}$. The online course assembles the world's best teachers so that students from all regions can listen to more professional courses by famous teachers. As a result, the University of students achieve the authority of knowledge without the limitation of location, especially in countries with inadequate education resources; it is beneficial for them to strengthen their academic performance and professional quality. Lee (2013) claims the feature of the online lesson is that students can master the autonomy of learning ${ }^{[4]}$. To be specific, each students' overall ability and course difficulty are different, and a majority of distance education is done on the Internet in advance, which means students can entirely master the subject by themselves. What is more, e-learning helps students devote more time and energy to the study instead of wasting time on transportation. For example, students can have a lesson at their home.

Improving learning motivation plays an essential role in cloud learning. Lee (2013) emphasises that learning motivation is relevant to the study environment, and it is beneficial to increase students' learning motivation by having a relaxed and comfortable environment ${ }^{[4]}$. Flexible time and location for college students to provide learning supply and emotional support, which is beneficial to form a good learning concept. Also, online discussion as a part of cloud course powerfully extends to improve students' emotions and perceived efficacy (Rienties, Brouwer and Baker,2013 and Lee, 2013) ${ }^{[4,8]}$. Study discussion as a cen- tral part of learning can find and correct some problems during the process of study. Compared with traditional analysis, online discussion extends the student's questions beyond the classroom and don not limited to limited classroom time, which means students can ask questions at any time when they find problems in their studies and get detailed answers in a short time. At the same time, they can check the issues mentioned by others and make up for the shortcomings in the cloud learning. As a result, the environment of learning and the atmosphere of discussion in the cloud are better than studying in the classroom.

\section{The Limitations of Learning in the Cloud}

Many students make progress of their academic performance in cloud learning, but this pattern of learning still exists some barriers. The professor Ni (2013) main researched the difference between face to face lessons and online lessons. According to this research, Ni found that the rate of dropout reaches $80 \%$ in an online class, and the completion of the traditional class is from $10 \%$ to $20 \%$ higher than the online course. This result indicates that students learning in the cloud always need stronger self-discipline. The reason for this phenomenon can be contributed to the pattern of cloud learning because online lessons are easy to get rid of reality. The main reason for many students in college who are willing to choose an online course instead of the traditional class is to achieve more freedom for themselves. Ni (2013) and Park, Nam and Cha (2012) also point out that both grade and self-evaluation of achieving learning objectives are the embodiment of measuring the learning effect. So, learning in the cloud does not affect students who have strong self-discipline ${ }^{[6-7]}$

In the process of learning, it is often easy for learners to subconsciously pay attention to only their psychological order while ignoring the logical order of the course itself (Park, Nam and Cha,2012) ${ }^{[7]}$. The majority of online lessons are recorded in advance, which makes students free choose every part they want to learn. Hence, some students give up some pieces of knowledge that they do not understand and uninterested in. Students would like to turn to a more accessible and attracted learning part to study. As a result, the correct order of learning materials is crushed, and this behaviour has a negative effect on the progress of students' academic performance and degree of mastery of knowledge.

Except for the high rate of dropout and incorrect order of study, some educational lessons are not suitable for cloud learning such as medicinal training. In 2018, Yuan as an academic medical expert claimed that clinical thinking ability and competence of meeting an emergency are 
the most critical content during the study of medicine, following the theoretical knowledge point learning, watching operation video and reading frontier literature ${ }^{[10]}$. The following content can be finished by learning in the cloud, but the experience of clinical ability needs learners to take part in various operations and observation many times. He also suggested that the particularity of medical education requires teachers to continually update their knowledge and encourage students to enter the hospital as soon as possible to begin clinical learning. Hence, medical education cannot depend on learning in the cloud, and it needs a more practical classroom to teach medical knowledge for students.

\section{The Outcome of Learning in the Cloud}

Not every student reaches the same learning effect via online courses. Learning in the cloud has become increasingly popular in the college education, and it is estimated that 5 to 7 million students participate in at least one online course each year (Allen and Seaman, 2015) ${ }^{[1] .}$ Jaggars and $\mathrm{Xu}$ (2016) further demonstrated that the quality of online interpersonal interaction relates positively to student grades $^{[3] .}$ They also found that the negative results of the online lesson are standard to be caused by students who are coming from a disadvantaged background or low study level students. If students who are addicted to enjoying entrainment activities instead of cloud lessons, the academic performance of cloud learning is not satisfied frequently. Those students do not focus on study knowledge and the high -quality study materials during cloud learning, and the grade of their study is unsatisfied. In some ways, the negative influence of the academic performance of cloud learning has not a relationship with study content and class style, and it is closed to the study attitudes of the learners.

Jaggars and $\mathrm{Xu}$ pointed out that the outcome of students in the class can be predicted in the field of interpersonal communication. There is another popular online education theory discussed that high-quality learning has a close association with the interaction of students and teacher (Allen and Seaman, 2015; Jaggars and Xu, 2016) ${ }^{[1,3]}$. Students meaningfully interacted with the instructor will enhance the development of the knowledge and reinforce learning content. What is more, this online interaction helps the learners to create productive relationships. For instance, the feedback from teachers is concrete, executable, timely, and it indicates students can improve their wrong parts faster. So, it is the best way to promote knowledge and skill application for students who like to communicate with teachers and classmates. In this way can realize the ideal learning goal.
Expect the internal factors of students; the type of lesson is another cause to influence the effect of learning in the cloud. The development of language learning in the field of technology and internet is dramatical to access the wealth language materials (Dudeney and Hockly, 2012) ${ }^{[2]}$. As a result, students achieve high-quality language education, which fitting in particularly studying minority language or other rare words because of the various materials online. Moreover, an online teacher from different countries and areas, students have the opportunity to choose the teacher. This studying mode can help students explore and practice the diversity of languages with local teachers, which is beneficial for society to preserve the dying language. For example, students learning American English can use the advantage of online education to select American teacher to study English and understand the history of American English at the same time.

\section{Conclusion}

Learning in the cloud or classroom study for students at university has been the subject of widespread debate and controversy. This paper has attempted to explain that learning in the cloud is more effective in terms of its function and advantages of students' study. It appears that various aspects were affected and improved by learning in the cloud, such as academic performance and learning motivation.

While online learning has some drawbacks on special lessons such as medical education, most lessons are suitable for this pattern of teaching and achieve great feedback from students. Hence, setting up an online course for students is essential, especially in college. At the same time, the designer of online lessons should spend more time and energy on expanding the range of online learning such as medical training and improve its structure, leading to making the better study environment for students.

\section{References}

[1] Allen, I. and Seaman, J. (2015). Tracking Online Education in the United States. Babson Survey Research Group.

[2] Dudeney, G. and Hockly, N. (2012). ICT in ELT: How did we get here and where are we going? ELT Journal, 66(4), Special issue, 533-542.

[3] Jaggars, S. and Xu, D. (2016). How do online course design features influence student performance? Computers and education, 95, pp.270-284.

[4] Lee, S. (2013). Investigating students' learning approaches, perceptions of online discussions, and students' online and academic performance. Computers 
\& education, 68, pp.345-352.

[5] Moore, L., Dickson, C. and Galyen, K. (2011). E-Learning, online learning, and distance learning environments: Are they the same? The Internet and Higher Education, 14(2), pp.129-135.

[6] Ni, A. (2013). Comparing the Effectiveness of Classroom and Online Learning: Teaching Research Methods. Journal of Public Affairs Education, 19(2), pp.199-215.

[7] Park, S., Nam, M. and Cha, S. (2012). University students' behavioural intention to use mobile learning: Evaluating the technology acceptance model. British journal of educational technology: journal of the Council for Educational Technology, 43(4), pp.592-605.
[8] Rienties, B., Brouwer, N. and Baker, S. (2013). The effects of online professional development on higher education teachers' beliefs and intentions towards learning facilitation and technology. Teaching and Teacher Education, 29, pp.122-131.

[9] Sangrà, A., Vlachopoulos, D. and Cabrera, N. (2012). Building an inclusive definition of e-learning: An approach to the conceptual framework. The International Review of Research in Open and Distributed Learning, 13(2), pp.145-159.

[10] Yuan, W. (2018). Research on the application of moocs in medical education. Journal of medical educational technology: journal of Jilin university of education, 22(3), pp.123-136. 